\title{
QUANTITATIVE DIVISION OF VEGETATION ECOTONES IN NORTHEAST CHINA
}

\author{
HAIBO, D. - ZHENGFANG, W.* - MING, L. - SHENGWEI, Z. - XIANGJUN, M. \\ College of Urban and Environmental Sciences, Northeast Normal University \\ No. 5268, Renming street, Changchun 130024, China \\ (phone: +86043185098717 ) \\ *Corresponding author \\ e-mail:wuzf1960@126.com
}

(Received $27^{\text {th }}$ July 2011; accepted $10^{\text {th }}$ February 2012)

\begin{abstract}
The present study aims to quantitatively divide the forest vegetation transition zones, the transition zone between humid forest and semi-humid meadow steppe and that between semi-humid meadow steppe and semi-arid grassland in Northeast China, using the rate of eco-climatic guarantee of the warmth and humidity index. The results indicated that there are two categories of vegetation ecotones in the Northeast China. 1) The first one has the major determinant of temperature factor. There are two sub classifications under this category. One lies in the place between cold temperate coniferous forest and temperate broad-leaved coniferous mixed forest, distributing mainly in the Northern Da Hinggan Mountains. The warmth index of it is the range of $37.8-52.2^{\circ} \mathrm{C}$ month. The other one locates at the place between warm temperate deciduous broad-leaved forest and temperate broad-leaved coniferous mixed forest, the warmth index value of which is $77.8-92.2^{\circ} \mathrm{C}$ month. It mostly distributes in the zone between Changbai Mountains and the mountains of Eastern Liaoning Province and, 2) the second category of vegetation ecotones is mainly decided by water factor. One is located between humid forest and semihumid meadow steppe, the humidity index of which is the range of $6.63-8.37 \mathrm{~mm} /\left({ }^{\circ} \mathrm{C}\right.$ month $)$, mainly distributing in the Heilongjiang-Songhua-Wusuli Rivers Plain (the Sanjiang Plain) and in the transition region between the Northeast China mountains area and the Liaohe-Songhua-Nenjiang Rivers Plain (the Songliao Plain). The other one is the transition zone between semi-humid meadow steppe and semi-arid grassland, whose humidity index value is $4.47-6.53 \mathrm{~mm} /\left({ }^{\circ} \mathrm{C}\right.$ month), mostly locating in the Hulun Buir plateau and the narrow and long region in the Songliao Plain.
\end{abstract}

Keywords: Vegetation ecotone; rate of eco-climatic guarantee; vegetation-climate classifications; Kriging interpolation

\section{Introduction}

Physical regional boundary lies the most significant change section of natural complex characteristics. It is the zone where qualitative changes between two adjacent and different natural complexes occur (Huang et al., 1999). There are obvious differences between the both sides of the boundary, not only in objective reality, climatic characteristics, vegetation and soil types of surface nature, but also in agricultural productivity, among others. The studies of dividing them were based on vegetation-climate classification. The early quantitative studies of vegetation-climate classification adopting single climate factors as classification indices began at the period from the $19^{\text {th }}$ century turning to the $20^{\text {th }}$ century. Then, since the $1940 \mathrm{~s}$, vegetationclimate classification had progressively researched based on synthetic climate indices, such as annual biotemperature (Holdridge, 1947), potential evapotranspiration (Thornthwaite, 1948), potential evapotranspiration and dry tolerance (Penman, 1956; McCulloch, 1965), net radiation and radiative dryness (Budyko, 1974), warmth, coldness and aridity/humidity (Kira, 1991) and humidity (Xu, 1985) and so on. 
Therefore, there are many bifurcations and disputes when dividing them (e.g. Fang and Yoda, 1991; Yang and Li, 1999).

There are mainly five viewpoints regarding the boundary between the cold temperate coniferous forest (CTF) and temperate broad-leaved coniferous mixed forest (TF) in Northeast China, which were reported by scholars (Xu, 1980; Xu et al., 2008), including 1. the boundary from southern slope of the Yilehuli mountain to Aihui; 2. the southwest of Huma; 3. moved the first boundary to southeast slightly; 4 . between $50^{\circ} \mathrm{N}$ and $50^{\circ} 20^{\prime} \mathrm{N}$; and 5 . the boundary of xin'an mountains vegetation, which was nearby the area of Aihui-Guosongou-south of Nenjiang River. Also, there were different opinions on the boundary between $\mathrm{TF}$ and warm temperate deciduous broad-leaved forest (WTF). Three of them were representative ( $\mathrm{Wu}, 2002)$, including 1 . the traditional 'Shenyang-Dandong' boundary based on the flora of Changbai Mountains and North China's flora; 2. the east of 'Shenyang-Dandong' boundary, which was from the Yalu River, through Kuandian-Fengchengdabao-Caohekou-Benxi-Nanzamu to Kaiyuan; and 3. the west of 'Shenyang-Dandong' boundary along the Liaoyang Laoheishan to Fengcheng Maokuishan based on warmth index. What's more, there are different opinions on the boundaries between humid forest (HF) and semi-humid meadow steppe (SMS) as well as between SMS and semi-arid grassland (SG), which the formation are mainly caused by water difference (Xu et al., 2008; Wu et al., 2003). These boundaries have been, in fact, obtained by forebears through the theoretical analysis and actual examination with practical values. However there were differences existed in those previous studies. The possible reasons are as follows. Firstly, the previous studies used different zoning indices ( $\mathrm{Ni}, 1998$ ), which inevitably led to difference. Secondly, climate controls the distribution of vegetation (Fang et al., 2002). Temperature and precipitation are the essential factors determining vegetation distributions (Fang and Yoda, 1990a; Woodward, 1987). Their long-term changes and short-term fluctuations are the major causes of the formation and distribution of eco-geographical boundary. The difference of research time would lead to different results and lastly, the systems of materials, energy, structure and function are different in the both sides of a boundary where it is the interlaced zone of two eco-systems. Therefore, it is difficult to distinguish the boundary in some spatial context, which should be the basic reason of difficulty in distinguishing the boundary. Namely, the 'boundary' should be, exactly, the 'zone'. To solve these problems, we believe that it is necessary to comprehend and analyze these 'boundaries' using the theory of vegetation ecological transition zone (vegetation ecotone).

Vegetation ecotone (VE), the transition zone between two adjacent eco-systems, has a set of unique characteristics determined by spatio-temporal scales and the strength of the interactions between the two adjacent eco-systems (Gosz, 1993). Its unique characteristics involve that 1) VE is rich in natural resources, 2) VE controls the adjacent eco-systems, 3) part of VE is generally the eco-vulnerable zone, and 4) ecorisks occur mainly within VE zone comparing with the adjacent eco-systems. According to all these aspects, VE becomes the key area of researching on the effects of climate change (Gao and Zhang, 1997; Goldblum and Rigg, 2005; Kharuk et al., 2010; Sjögersten and Wookey, 2009). Guo (2001) studied the scientific significance of the forest VE between Da Hinggan Mountains and Xiao Xinggan Mountains to global climate change. Ma et al. (2006) studied the ecological niche of constructive species of a VE in Heng Mts. Shanxi. Huang and Wang (2010) studied the vegetation change of ecotone in west of Northeast China plain using time-series remote sensing data. 
Dividing VE, especially quantitatively dividing, has significant scientific meaning. For these reasons mentioned above, the authors focus, thus, on quantitatively dividing VE using the theory of rate of eco-climatic guarantee. The cultivation and deforestation have led to serious damage of natural vegetation and environment, especially in VE in most part of Northeast China in the past 200 years. Therefore, the authors perform, specially, the analysis in Northeast China. It is expected to be valuable for the restoration and reconstruction of eco-system in transition zones of Northeast China.

\section{Materials}

The original data used in this study consist of daily precipitation and temperature obtained from the National Weather Service. There are totally 131 meteorological stations with data available from 1951 onwards in Northeast China. For many stations there are incomplete or inadequate data in the early operating period 1951-1960. The analysis period in this study is, therefore, confined to 1961-2007. We selected data from 93 stations and from those data we performed the analysis. The distribution of the 93 stations in Northeast China is presented in Fig. 1. We can see that the sites are evenly spaced in the study area. As for the study area, Northeast China is located between $115^{\circ} 52^{\prime}-135^{\circ} 09^{\prime} \mathrm{E}$ and $38^{\circ} 72^{\prime}-53^{\circ} 55^{\prime} \mathrm{N}$, which covers Heilongjiang Province, Jilin Province, Liaoning Province, as well as Chifeng, Tongliao, Hulun Buir City and Hinggan League in Eastern Inner Mongolia (Fig. 1). Da Hinggan Mountains is located at the northwest, Xiao Hinggan Mountains at the northeast, and Changbai Mountains, composed of several series of parallel mountains, is locate at the southeast in the internal region of Northeast China. The Japan Sea is in the east while the Yellow Sea Bohai Seas are located in the south. The Mongolian plateau is situated in the north. The study area is a physically geographical region.

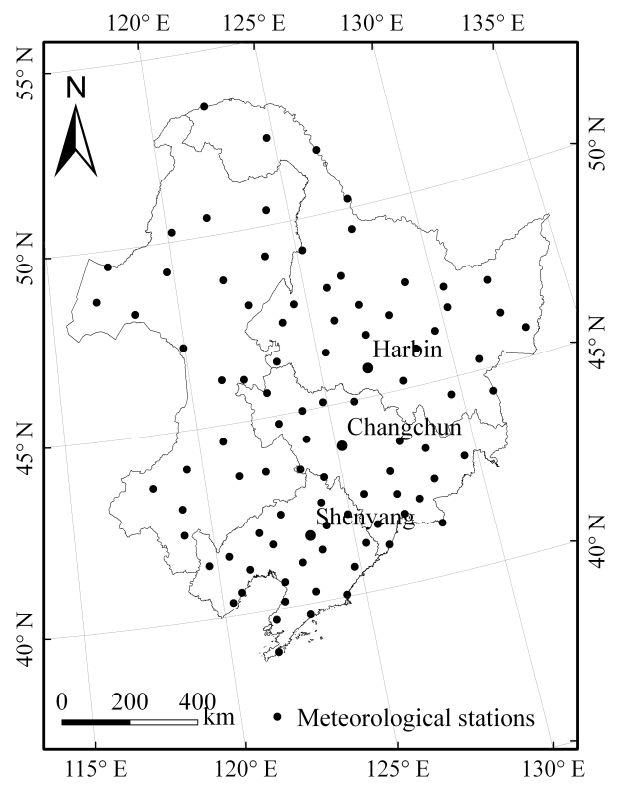

Figure 1. Distribution of meteorological stations in Northeast China 


\section{Methods}

There are mainly four vegetation-climate classifications for dividing ecogeographical boundaries. They are Penman (1956), Thornthwaite (1948), Holdridge (1947) and Kira (1991) models, respectively. The Penman model can calculate the index precisely and has physical significance. However, this model is limited in actual applications because that the calculation of it is intricate, and that it needs too many parameters and some of them are not recorded in general meteorological stations, such as the defective value of vapour pressure $(\mathrm{Ni}, 1998)$. For Thornthwaite model, there are three major reasons that show this model's deficiency as follows. First, temperature, which is as the major variable of the model, is not the most perfect indicator of evapotranspiration rate. Second, this model was put forward by Thornthwaite using the data of Eastern United States, which couldn't be suitable for all places and, the last, if the mean monthly temperature is below $0^{\circ} \mathrm{C}$, the corresponding monthly PE value will be set as $0 \mathrm{~cm}$, which is suspected by many scholars. Especially in Northeast China, the stations generally have 3-5 months which the mean month temperature is below $0{ }^{\circ} \mathrm{C}$, and mostly stations have 5 months. The vegetation divisions of Northeast China based on this model may be not the optimal model, such as the study by $\mathrm{Wu}$ (2002). Holdridge method was deemed to be good vegetation-climate classification (Ni, 1998). Whereas we adopt the Kira model developed from the researches on the relationship between vegetation and climate in East Asia for calculation of the warmth index WI of the vegetation. Because sufficient evidence confirms that this model excellently describes the relationships between thermal climate and the macro-distribution of plant formations (Fang and Yoda, 1989). Kira (Fang and Yoda, 1990b), and Yim and Kira (1975) and Yim (1977) effectively divided the distribution of forest zones in Japan and Korea Peninsula using the WI, respectively. The index, which was obtained in the area where the relationship between temperature and precipitation is simple, is suitable for regions where temperature exhibits a good relationship with precipitation; this is especially true for Northeast China (Ren and Yang, 1961) where the rains mainly occur in summer. Therefore, we quantitatively divided the VEs by the methods of rate of ecoclimatic guarantee based on Kira's climate classification in the Northeast China.

\section{Calculations for the WI and HI}

These indices were calculated using the following equations:

$$
\begin{gathered}
W I=\sum\left(t_{\mathrm{n}}-5\right) \\
H I=P / W I
\end{gathered}
$$

where $t_{\mathrm{n}}$ is the $>5^{\circ} \mathrm{C}$ monthly mean temperature and $P(\mathrm{~cm})$ is the amount of annual precipitation.

In accordance with the actual conditions in Northeast China, $W I=45^{\circ} \mathrm{C}$ month was used as the boundary between $\mathrm{CTF}$ and TF; $W I=85^{\circ} \mathrm{C}$ month was used as the boundary between WTF and TF; $H I=7.5 \mathrm{~mm} /\left({ }^{\circ} \mathrm{C}\right.$ month $)$ was adopted as the boundary between $\mathrm{HF}$ and SMS; $H I=5.5 \mathrm{~mm} /\left({ }^{\circ} \mathrm{C}\right.$ month $)$ was used as the boundary between SMS and SG (Ni, 1998; Xu et al., 2008). 


\section{VE divisions}

We calculate the possible and stable limits of vegetation using rate of eco-climatic guarantee based on the eco-geographical boundary, afterwards we obtain the VE. We assume that there are two adjacent eco-systems A and B growing perennials or crops, and the demand of $\mathrm{A}$ for the $W I$ (or $H I$ ) is more than that of B. First, the dominant species of the two eco-systems compete, and both species have equal chances of survival nearby the eco-geographical boundary between $\mathrm{A}$ and $\mathrm{B}$. The guarantee rate of them is $50 \%\left(W I_{50}\right.$ or $\left.H I_{50}\right)$. With increasing $W I$ (or $H I$ ) on one side of $W I_{50}$ (or $H I_{50}$ ), the competitiveness of the dominant species of $\mathrm{B}$ declines and their chances of survival are reduced. By contrast, the survival chances of the species of A increase. A species dominate, whereas B species can grow only in certain habitats when the WI (or $H I$ ) increases to $W I_{90}$ (or $H I_{90}$ ), i.e., if the rate of guarantee is $90 \%$ (Agricultural Meteorology, Shenyang Agricultural University, 1982). Thus, the lower limit of the stable distribution of $\mathrm{A}$ is $W I_{90}$, which is also a limit of the transition zone between $\mathrm{A}$ and $\mathrm{B}$. By contrary, the decrease in the WI or $H I$ on the other side of $W I_{50}$ (or $H I_{50}$ ) results in the decline of the competitiveness of A species. Conversely, the competitiveness of $\mathrm{B}$ species is enhanced. When the $W I$ (or $H I$ ) drops to $W I_{10}$ (or $H I_{10}$ ), that is, the rate of guarantee is $10 \%$. A species can occur only in certain habitats whereas B species dominate. This dominance constitutes the upper limit of the stable distribution of B species. It is also the other limit of the transition zone between A and B. For the annual plant or crop, they are similar to the perennials, while their growth generally requires $80 \%$ guarantee rate. According to Fig. 2, we can intuitively understand the transition zone as follow:

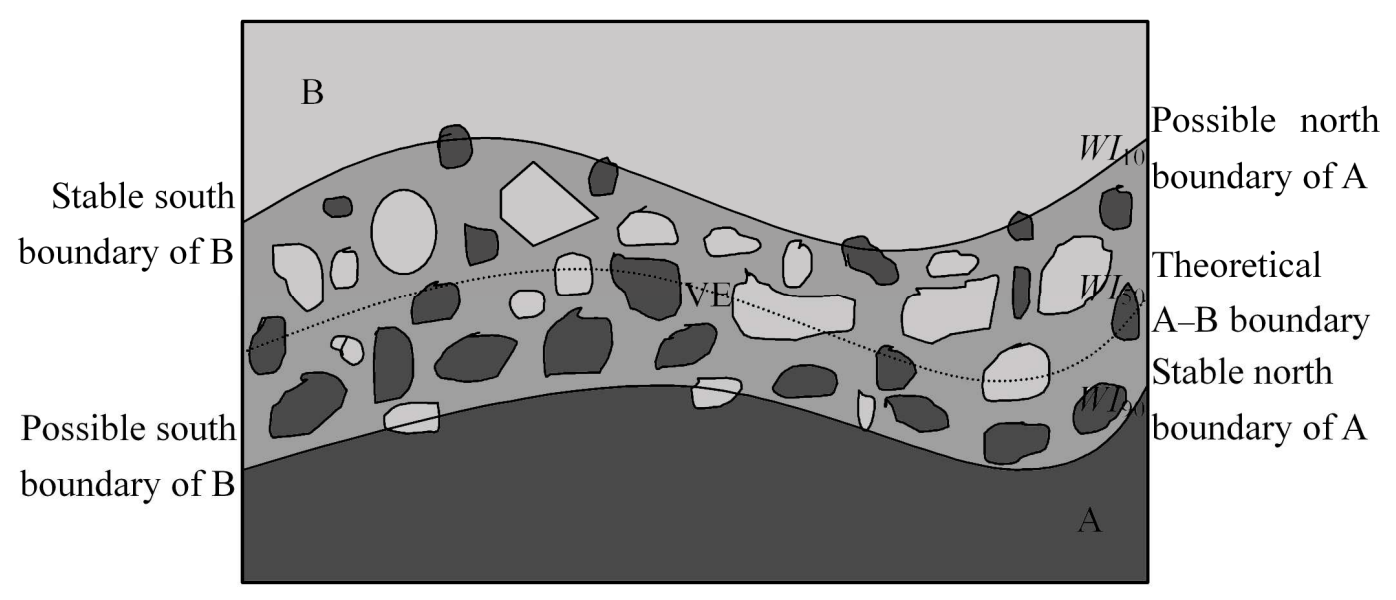

Figure 2. The schematic diagram of vegetation ecotone (VE)

We present the correlation and regression analysis between $W I$ and $\geq 10^{\circ} \mathrm{C}$ accumulated temperature $\left(T_{\geq 10^{\circ} \mathrm{C}}\right)$ with the 93 meteorological stations in Northeast China, then obtain the equation:

$$
W I=0.027 \times T_{\geq 10^{\circ} \mathrm{C}}-7.552
$$


Table 1. Correlation and regression analyses between WI and $T_{\geq 10^{\circ} \mathrm{C}}$

\begin{tabular}{c|c|c|c|c|c}
\hline Correlation coefficient $(\boldsymbol{R})$ & $\boldsymbol{R}^{\mathbf{2}}$ & Sig. & Regression coefficient $(\boldsymbol{a})$ & Sig. & Constant \\
\hline 0.997 & 0.994 & 0.000 & 0.027 & 0.000 & -7.552 \\
\hline
\end{tabular}

${ }^{* *}$ Regression coefficient is significant at the 0.05 level $(2-$ tailed $)$.

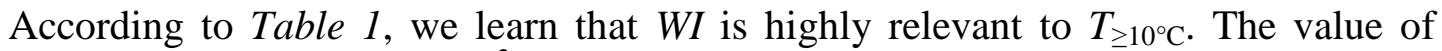
coefficient of determination $R^{2}$ is 0.994 (Sig. is 0), which shows that Eq. (3) is available. Additionally, we calculate the change range of $T_{\geq 10^{\circ} \mathrm{C}}$ of Northeast China in 1961-2007. The mean variation range is $-388^{\circ} \mathrm{C}$ to $451^{\circ} \mathrm{C}$, which also indicates that Northeast China belong to unstable climate type, obviously. When a guarantee rate of $90 \%$ was calculated using the guarantee rate formula, $\Delta T_{\geq 10^{\circ} \mathrm{C}}=266^{\circ} \mathrm{C}$ (Agricultural Meteorology, Shenyang Agricultural University 1982). Then $\Delta W I=0.027 \times \Delta T_{\geq 10^{\circ} \mathrm{C}}=$ $7.2^{\circ} \mathrm{C}$ month was obtained using Eq. 3. Thus, $W I_{90}=52.2^{\circ} \mathrm{C}$ month is the upper limit of the VE between CTF and TF. Similarly, the values of the limits of the other transition zones are calculated. Subsequently, the guarantee rate of the perennials or crops in each meteorological station is calculated based on the standard deviation formula of guarantee rate (Agricultural Meteorology, Shenyang Agricultural University, 1982).

$$
\begin{gathered}
W I_{90}=W I_{50}+1.28 \sigma_{\mathrm{WI}} \text { or } H I_{90}=H I_{50}+1.28 \sigma_{\mathrm{HI}} \\
W I_{10}=W I_{50}-1.28 \sigma_{\mathrm{WI}} \text { or } H I_{10}=H I_{50}-1.28 \sigma_{\mathrm{HI}}
\end{gathered}
$$

For annual plant or crop:

$$
\begin{gathered}
W I_{80}=W I_{50}+0.84 \sigma_{\mathrm{WI}} \text { or } H I_{80}=H I_{50}+0.84 \sigma_{\mathrm{HI}} \\
W I_{20}=W I_{50}-0.84 \sigma_{\mathrm{WI}} \text { or } H I_{20}=H I_{50}-0.84 \sigma_{\mathrm{HI}}
\end{gathered}
$$

where $W_{50}$ and $H I_{50}$ are the boundaries of the temperature and water between different vegetation zones, respectively; 1.28 and 0.84 are the coefficients of dispersion of the normal distribution (when bias coefficient is 0 ); $\sigma_{\mathrm{WI}}$ and $\sigma_{\mathrm{HI}}$ are standard deviations of $W I$ and $H I$, respectively.

\section{Interpolation of the WI and $\mathrm{HI}$}

According to the raw data and methods mentioned above, we have obtained the WI and $H I$ values of the 93 sites in the study area. However, this study needs the data of the entire surface. Therefore, the values at unknown locations have to be estimated or interpolated by some special methods. By placing an evenly spaced site over the area for which we have known values we can obtain an estimated surface. Kriging interpolation (Oliver et al., 1990; Mason et al., 1994), developed by Matheron and Krige (Cressie, 1992), is based on the theory of regionalized variables. The basic premise of Kriging interpolation is that each unknown point can be estimated by the weighted sum of the known points, but unlike inverse distance weighted interpolation, the weights depend on the spatial correlation and the function values of the data set (i.e., on the variogram and anisotropism), which is the biggest advantage of the Kriging technique over all the other classical statistical procedures. Kriging method also 
quantifies the estimation variance, which will lead to define the precision of the resulting estimates. For more information, we refer the readers to the Refs. (Cekli and Gunes, 2006; Davis, 1986; Largueche, 2006). In this study, the spatial interpolation of the $W I$ and $H I$ values is, therefore, presented using the Kriging technique.

\section{Results and Discussions}

\section{CTF-TF VE division}

Based on the WI, the boundary between cold temperate zone and temperate zone is along the 'Southern Aershan-Southern Yakeshi-central Oroqen Autonomous Bannercentral Huma-Western Tahe-Mohe'. On the basis of the guarantee rate formula, $W I_{90}=$ $52.2^{\circ} \mathrm{C}$ month is as the contour line from Southern Eerguna southward through Eastern Chen Barag Banner and central Evenk Autonomous Banner to Southern Xin Barag Left Banner, then along Southern Aershan northward through Southern Yakeshi, Western Arun Banner, central Oroqen Autonomous Banner, central Huma to Eastern Tahe. The contour line represents the stable north limit of TF and the possible south limit of CTF, which is the upper limit of this VE (Fig. 3). $W I_{10}=37.8{ }^{\circ} \mathrm{C}$ month is the contour line from Southern Eerguna, through Eastern Chen Barag Banner and central Yakeshi, along central Oroqen Autonomous Banner, through Western Huma and Tahe to Mohe, represents the possible north limit of TF and the stable south limit of CTF. That is, this line is the upper limit of this VE (Fig. 3). The annual average temperature is about -2.6$0^{\circ} \mathrm{C}, T_{\geq 10^{\circ} \mathrm{C}}$ about $1500-2000^{\circ} \mathrm{C}$, annual precipitation about $340-480 \mathrm{~mm}$ in this VE. And the north boundary of this VE is basically consistent with the north boundary of Quercus mongolica.

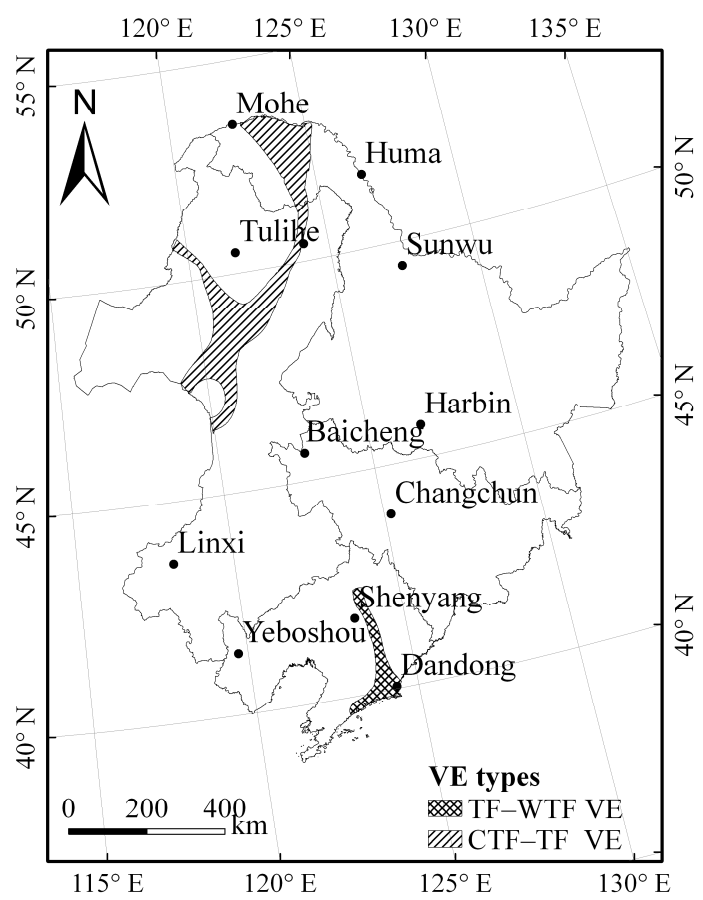

Figure 3. Latitudinal (vertical in Mountains) VEs in Northeast China. Abbreviations: vegetation ecotone (VE), cold temperate coniferous forest (CTF), temperate broad-leaved coniferous mixed forest (TF), warm temperate deciduous broad-leaved forest (WTF) 
In addition, there are broad-leaved coniferous mixed forest zone, coniferous forest zone, erman's birch forest zone and alpine tundra zone from the basal zone to the summit in Changbai Mountains existed, respectively. Therefore there is a transition zone between broad-leaved coniferous mixed forest zone and coniferous forest zone nearby $1100 \mathrm{~m}$.

\section{TF-WTF VE division}

The $W I$ value of the boundary between TF and WTF is $W I_{50}=85^{\circ} \mathrm{C}$ month. On the basis of the guarantee rate formula, $W I_{90}=92.2{ }^{\circ} \mathrm{C}$ month is as the contour line from central Zhuanghe, along the border of Youyan and Fengcheng northward to Benxi, then through Shenyang to Tieling, which constitutes the stable upper boundary of WTF and the possible lower boundary of TF. This contour line is also the upper limit of this VE (Fig. 3). And the contour line $W I_{10}=77.8^{\circ} \mathrm{C}$ month is obtained from Northeastern Dandong northward along the Eastern Fengcheng, through Benxi, Eastern Fushun, then northward to central Tieling, which forms the possible upper boundary of WTF and the stable lower boundary of TF. Namely, this line is the lower limit of this VE (Fig. 3). We name it as 'Shenyang-Dandong transition zone'. Not only the terrain and soil, but also flora shows obvious transition features in this transition zone. Terrain is gradually from Jilin Hada Ling and Longgang Mountains in Changbai Mountains transition to the Qianshan Mountains of Eastern Liaoning; soil gradually changes from dark brown forest soil to brown forest soil; the two major floras, North China's flora and flora of Changbai Mountains, interlace distribution in this transition zone. And the annual average temperature is about 5.6-9.4 ${ }^{\circ} \mathrm{C}, T_{\geq 10^{\circ} \mathrm{C}}$ about $3000-3400^{\circ} \mathrm{C}$, annual precipitation about $570-920 \mathrm{~mm}$ in this transition zone.

\section{HF-SMS VE division}

The forest and the meadow steppe distribute widely in the humid mountains (e.g., Changbai Mountains, Zhangguangcai Mountains, Xiao Hinggan Mountains and Da Hinggan Mountains etc.) and in the central region in the Northeast China, respectively. Hence, a forest-meadow steppe transition zone must exist between them. The terrain is composed mostly of 200-300 m altitude hills and mounds. And the forests interlace distribution with meadow in the transition zone between the mountains and plains, which form the transitional vegetation type-forest-meadow steppe between $\mathrm{HF}$ and SMS. The $H I$ value of the boundary between them is $7.5 \mathrm{~mm} /\left({ }^{\circ} \mathrm{C}\right.$ month $)$, namely, $H I_{50}$ $=7.5 \mathrm{~mm} /\left({ }^{\circ} \mathrm{C}\right.$ month $)$. On the basis of the guarantee rate formula, we divide the contour line $H I_{90}=8.37 \mathrm{~mm} /\left({ }^{\circ} \mathrm{C}\right.$ month) into four parts (Fig. 4). The first part originates in Southern Eerguna, along Southwestern Yakeshi southward to Northern Aershan. The second part derives from Northern Horqin Right Wing Front Banner, northward to Zhalantun, Arong Banner, then turns northeastward through Oroqen, Huma to Tahe. The third part originates in Hehe, southward along Sunwu, Beian, Suiling and Tieli, then turns to Tangyuan until the east of Luobei. The last part derives from the foothills of Western Changbai Mountains, northward to Shangzhi, then turns southward along the southwest border of Mudan River, the northeast border of Dunhua and the northeast border of Antu to Longjing. Those parts constitute the stable limit of the forest and the possible limit of the meadow steppe, which is also the upper limit of the transition zone. The contour line, $H I_{10}=6.63 \mathrm{~mm} /\left({ }^{\circ} \mathrm{C}\right.$ month), which constitutes the possible limit of the forest and the stable limit of the 
meadow steppe, is divided into two parts (Fig. 4). The first part derives from Southern Eerguna southward across Eastern Chen Barag Banner and Evenk Autonomous Banner until Eastern Xin Barag Left Banner. The second part originates in the Horqin Right Wing Front Banner, northward to Zhalantun, Arong Banner and Nenjiang River, then turns southward along Keshan, Mingshui, Bayan, Acheng, Yushu, Changchun, Tieling, Shenyang, and Liaoyang to Western Zhuanghe. All above constitute the lower limit of this VE.

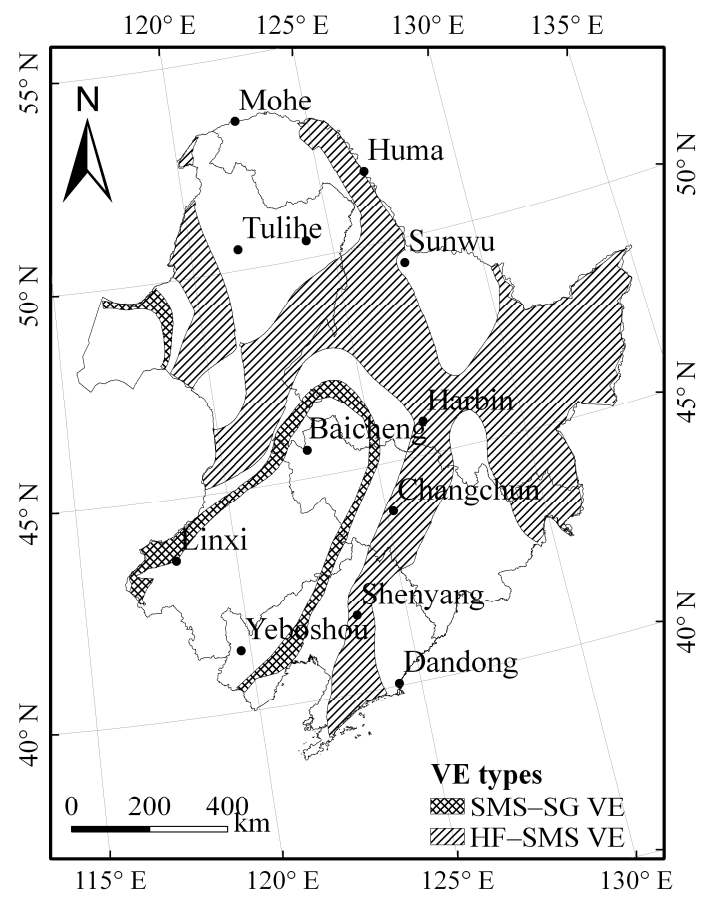

Figure 4. Longitudinal VEs in Northeast China. Abbreviations: vegetation ecotone (VE), humid forest $(H F)$, semi-humid meadow steppe (SMS), semi-arid grassland ( $S G)$

The annual average temperature is about $2-5.7^{\circ} \mathrm{C}, T_{\geq 10^{\circ} \mathrm{C}}$ about $2400-3200^{\circ} \mathrm{C}$, annual precipitation about $450-700 \mathrm{~mm}$ in this VE. The spatial distribution of this transition zone can be divided into three parts. One shows half ring around the Songliao Plain. Another is in the junction area between Hulun Buir plateau and Western Da Hinggan Mountains and, the last one is in Sanjiang Plain. The black soil zone is almost coincident with this transition zone, in which vegetation type is forest-meadow steppe vegetation.

\section{SMS-SG VE division}

According to eco-climatic law, a guarantee rate of $80 \%$ should be able to satisfy the eco-climatic demands of the annual vegetation growing in the Songliao Plain and Hulun Buir Plateau (Zhao and Zhang, 1999). On the basis of the guarantee rate formula, we conclude that $H I_{80}=6.53 \mathrm{~mm} /\left({ }^{\circ} \mathrm{C}\right.$ month $)$ and $H I_{20}=4.47 \mathrm{~mm} /\left({ }^{\circ} \mathrm{C}\right.$ month $)$ constitute the upper and lower limits of SMS-SG VE, respectively (Fig. 4). This VE is quite narrow, which originates in Western Chen Barag Banner, along Western Evenk Autonomous Banner to central Xin Barag Left Banner nearby Hulun Buir plateau. It shows tongue-shaped distribution around the Songliao Plain, and derives from Linxi, along Bairin Left Banner, central Jarud Banner, Horqin Right Wing Rear Banner, Jalaid Banner, Southern Lindian, Southern Anda, Western Zhaodong, Western Fuyu, Western 
Nongan, Changling, Horqin Left Wing Rear Banner, Zhangwu, and Western Heishan to Jianchang nearby the Sonliao Plain. The annual average temperature is about $4-7^{\circ} \mathrm{C}$, $T_{\geq 10^{\circ} \mathrm{C}}$ about $2500-3200^{\circ} \mathrm{C}$, annual precipitation about $350-500 \mathrm{~mm}$. The soil is mainly chestnut soil in the transition zone of Western Da Hinggan Mountains, mostly meadow chernozem and carbonate meadow soil in the transition zone of Eastern Northeast Plain. The vegetation types are both forbs meadow and dry grassland. The representative plants species include Aneurolepidium chinense, Stipa Baicalensis, Stipa grandis, Artemisia frigida, and Agropyron cristatum etc. This VE is quite narrow, which changes complexity, is more sensitive to climate change, and also more vulnerable damage than other transition zone. Therefore protection of such a transition zone should be taken seriously.

\section{Discussions}

To date, there are five kinds of boundaries between cold temperate zone and temperate zone in Northeast China divided in the previous studies (Xu et al., 2008). The northernmost boundary is the southwest of Huma (Liu et al., 1959). The southernmost boundary is along Aihui-Guosonggou to the south of Nenjiang River (Xu et al., 2008). The CTF-TF VE divided in this study locates between the two boundaries (Fig. 3). Meanwhile, intensive works have been carried out to divide the boundary between TF and WTF (e.g. Hou, 1963; Zhou, 1981; Xu et al., 2003). However, there are obvious differences among them. The result of the division of TF-WTF VE in this study is similar as that obtained by $\mathrm{Xu}$ et al. (2003), although they just divided the boundary between TF and WTF. That is, the 'Shenyang-Dandong transition zone' basically conforms to the actual situation. The area growing zonal vegetation, such as Carpinus cordata, Abies holophylla and broad-leaved Korean pine forest, is the north region of the transition zone, which distributes in southern region of TF. Natural Korean Pine disappears nearly in this transition zone. The secondary forests distribute widely in Eastern Liaoning Province Mountains, such as Fraxinus mandshurica, Juglans mandshurica, Phellodendron amurense, Tilia amurensis, Fraxinus rhynchophylla, Corylus mundshurica and Sambueus williamsli.

\section{Validation on the $\mathrm{VE}$ divisions}

In this section, we validate the VE divisions using the Vegetation Map of People's Republic of China (1: 1000 000) compiled chiefly by Institute of Botany, Chinese Academy of Sciences in 1979-2007 (Editorial Committee of Vegetation Map of China, Chinese Academy of Sciences 2007). We extract the vegetation map of Northeast China, and divide the vegetation into 10 vegetation types. Fig. 5 shows the distributions of the vegetation types in Northeast China. Subsequently, we calculate the area of the four VEs divided in this study, as well as the area of the major vegetation types discussed in this study. The results are presented in Table 2. 


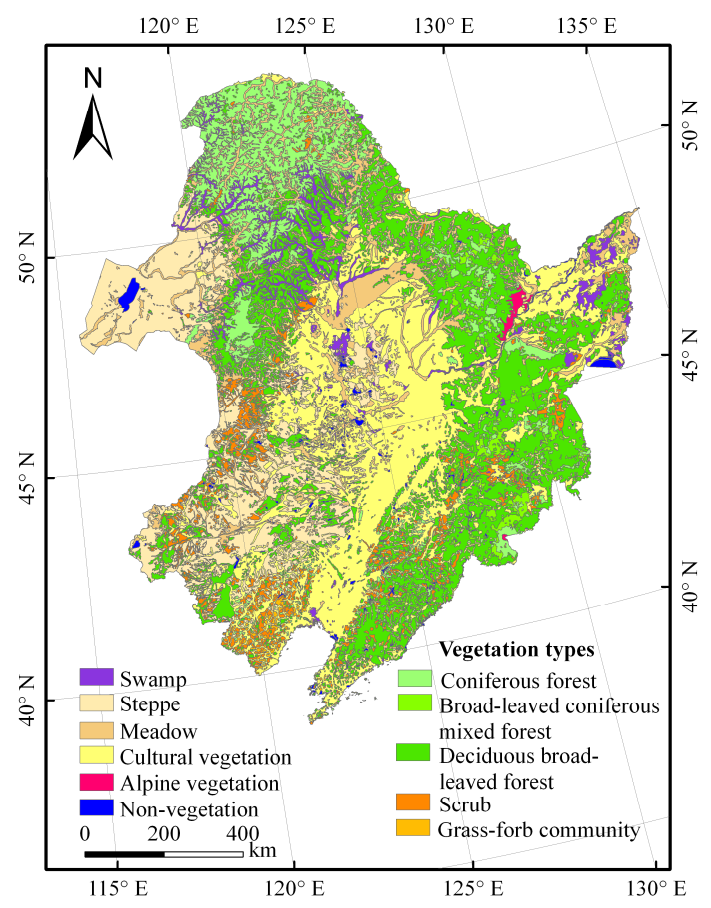

Figure 5. Vegetation types of Northeast China

Table 2. The validation data of the VE divisions

\begin{tabular}{|c|c|c|c|c|c|c|c|c|}
\hline 年 & \multicolumn{2}{|c|}{ CTF-TF } & \multicolumn{2}{|c|}{ TF-WTF } & \multicolumn{2}{|c|}{ HF-SMS } & \multicolumn{2}{|c|}{ SMS-SG } \\
\hline Total area $\left(\mathrm{km}^{2}\right)$ & \multicolumn{2}{|l|}{63683.7} & \multicolumn{2}{|c|}{11313.3} & \multicolumn{2}{|l|}{481257} & \multicolumn{2}{|c|}{59166.3} \\
\hline Vegetation types & CTF & $\mathrm{TF}$ & $\mathrm{TF}$ & WTF & $\mathrm{HF}$ & SMS & SMS & SG \\
\hline Area $\left(\mathrm{km}^{2}\right)$ & 23709.8 & 14749.1 & 1411.6 & 5353.4 & 212524 & 90891.5 & 9521.8 & 20348.2 \\
\hline Area ratio & \multicolumn{2}{|c|}{ CTF $:$ TF $=1.61: 1$} & \multicolumn{2}{|c|}{ TF $: \mathrm{WTF}=0.26: 1$} & \multicolumn{2}{|c|}{ HF $:$ SMS $=2.34: 1$} & \multicolumn{2}{|c|}{ SMS : SG $=0.47: 1$} \\
\hline
\end{tabular}

Abbreviations note: vegetation ecotone (VE), cold temperate coniferous forest (CTF), temperate broad-leaved coniferous mixed forest (TF), warm temperate deciduous broad-leaved forest (WTF), humid forest (HF), semi-humid meadow steppe (SMS), semi-arid grassland (SG).

The validation data presented in Table 2 is obtained from the vegetation map of Northeast China using ARCMAP 9.3. We calculate the total area of the CTF-TF, TFWTF, HF-SMS, and SMS-SG VEs, and analyze the area ratio of the discussed vegetation types in the four VEs, respectively. According to Table 2, it can be easily found that each VE covers mostly the vegetation types of the both sides of the VE. The variation range of the area ratio of the discussed vegetation types in each VE is 0.26 to 2.34. The most perfect VE division is CTF-TF VE with the area ratio of CTF : TF = $1.61: 1$. The last one is, unfortunately, TF-WTF VE with the area ratio of TF : WTF = $0.26: 1$. In this VE, the area of WTF is bigger than that of TF, increasing by about 4 times. The major reason may be that the marine climate influences the vegetation growth, e.g. the warm and humid airflow is beneficial to the growth of WTF in Eastern Liaoning Province Mountains. We can say, in summary, that the VEs divided in this 
study fit in with the actual vegetation distribution of Northeast China, which is, therefore, strong evidence that the method of dividing VE in this study is believable and valuable. Nevertheless, there are more works to do. For example, the division indexes need to be improved. The VEs may vary with time due to the climate changes, human activities and other disturbances. It is important to study of the relationships between the changes of VE and the variations mentioned above or the interactions of them.

\section{Conclusions}

The eco-climatic factors consisting of temperature and water are the energy and material foundation of determining VE. It is also an important basis for researching on vegetation distribution. In this paper, we employed the existing models to quantitatively divide the VEs of Northeast China based on the rate of eco-climatic guarantee.

There are two categories of VEs in Northeast China. 1) The latitudinal VEs mostly determined by temperature factor. One is CTF-TF VE, whose $W I$ value is $37.8-52.2{ }^{\circ} \mathrm{C}$ month, mainly distributing in the Northern Da Hinggan Mountains. The other one is WTF-TF VE, the $W I$ value of which is $77.8-92.2{ }^{\circ} \mathrm{C}$ month, mostly distributing in the zone between Changbai Mountains and the mountains of Eastern Liaoning Province. 2) The longitudinal VEs mainly decided by water factor. One is HF-SMS VE, the $H I$ value of which is $6.63-8.37 \mathrm{~mm} /\left({ }^{\circ} \mathrm{C}\right.$ month $)$, mainly distributing in the Sanjiang Plain and in the transition region between Northeast China mountains area and the Songliao Plain. The other one is SMS-SG VE, whose $H I$ value is $4.47-6.53 \mathrm{~mm} /\left({ }^{\circ} \mathrm{C}\right.$ month $)$, mostly locating in the Hulun Buir plateau and the narrow and long region in the Songliao Plain.

Acknowledgements. This study was financially supported by the Major State Basic Research Development Program of China (973) (grant no. 2009CB426305). We would like to give many thanks to Du Xing for help with the literature search.

\section{REFERENCES}

[1] Agricultural Meteorology, Shenyang Agricultural University (1982): Agroclimatology. Mimeograph (in Chinese).

[2] Budyko, M.I. (1974): Climate and Life. - New York, Academic Press.

[3] Cekli, H.E., Gunes, H. (2006): Spatial resolution Enhancement and reconstruction of mixed convection data using Kriging method. - ASME International Mechanical Engineering Congress and Exposition 3: 447-456.

[4] Cressie, N. (1992): Statistics for spatial data. - Terra Nova 4(5): 613-617.

[5] Davis, J.C. (1986): Statistics and data analysis in geology. - New York: John Wiley \& Sons.

[6] Editorial Committee of Vegetation Map of China, Chinese Academy of Sciences (2007): Vegetation Map of The People's Republic of China (1 : 1000 000). - Beijing: The geological Publishing House.

[7] Fang, J.Y., Yoda, K. (1989): Climate and vegetation in China. II. Distribution of main vegetation types and thermal climate. - Ecological Research 4: 71-83.

[8] Fang, J.Y., Yoda, K. (1990a): Climate and vegetation in China. III. Water balance and distribution of vegetation. - Ecological Research 5: 9-23.

[9] Fang, J.Y., Yoda, K. (1990b): Climate and vegetation in China. IV. Distribution of tree species along the thermal gradient. - Ecological Research 5: 291-302. 
[10] Fang, J.Y., Yoda, K. (1991): Climate and vegetation in China. V. Effect of climatic factors on the upper limit of distribution of evergreen broadleaf forest. - Ecological Research 6: 113-125.

[11] Fang, J.Y., Song, Y.C., Liu, H.Y., Piao, S.L. (2002): Vegetation-climate relationship and its application in the division of vegetation zone in China. - Acta Botanica Sinica 44(9): 1105-1122.

[12] Gao, Q., Zhang, X.S. (1997): A simulation study of responses of the Northeast China transect to elevated $\mathrm{CO}_{2}$ and climate change. - Ecological Applications 7(2): 470-483.

[13] Goldblum, D., Rigg, L.S. (2005): Tree growth response to climate change at the deciduous-boreal forest ecotone, Ontario, Canada. - Canadian Journal of Forest Research 35(11): 2709-2718.

[14] Gosz, J.R. (1993): Ecotone hierarchies. - Ecological Applications 3(3): 369-376.

[15] Guo, Q.X. (2001): Scientific significance of the forest vegetation ecotone between Daxing'an Mountains and Xiaoxing'an Mountains to study of global climate change. Journal of Forestry Research 12(2): 93-96.

[16] Holdridge, L.R. (1947): Determination of world plant formations from simple climatic data. - Science 105: 367-368.

[17] Hou, X.Y. (1963): Discussion on the problems for the previous scheme of vegetation divisions in China. - Acta Phytoecologia et Geobotanica Sinica 1(1-2): 1-23. (in Chinese)

[18] Huang, B.W., Zhen, D., Zhao, M.C. (1999): Modern physical geography. - Beijing: Science Press. (in Chinese)

[19] Huang, F., Wang, P. (2010): Vegetation change of ecotone in west of Northeast China plain using time-series remote sensing data. - Chinese Geographical Science 20(2): 167175.

[20] Kharuk, V.I., Im, S.T., Dvinskaya, M.L. (2010): Forest-tundra ecotone response to climate change in the Western Sayan Mountains, Siberia. - Scandinavian Journal of Forest Research 25(3): 224-233.

[21] Kira, T. (1991). Forest ecosystems of East and Southeast Asia in global perspective. Ecological Research 6: 185-200.

[22] Largueche, F.Z.B. (2006): Estimating Soil Contamination with Kriging Interpolation Method. - American Journal of Applied Sciences 3(6): 1894-1898.

[23] Liu, S.N., Feng, Z.W., Zhao, D.C. (1959): Problems on regionalization of Chinese vegetation. - Acta Botanica Sinica 8(2): 87-105. (in Chinese)

[24] Ma, X.Y., ShangGuan, T.L., Zhang, F. (2006): Ecological niche study of constructive species of the vegetation ecotone of temperate grassland and warm-temperate deciduous broad-leaved forest - Taking the vegetation on the south and north slopes of Heng Mts. Shanxi for example. - Bulletin of Botanical Research 27(5): 610-617.

[25] Mason, D.C., O'Conaill, M., McKendrick, I. (1994): Variable resolution block kriging using a hierarchical spatial data structure. - Journal of Geographical Information Systems 8(5): 429-449.

[26] McCulloch, J.S.G.. (1965): Table for the rapid computation of the Penman estimate of evaporation. - East African Agricultural and Forestry Journal 1: 286-295.

[27] Ni, J. (1998): Indexes of vegetation-climate classification and its applications. - Chinese Journal of Ecology 17(5): 33-44. (in Chinese)

[28] Oliver, M.A., Webster, R. (1990): Kriging: a method of interpolation for geographical information systems. - Journal of Geographical Information Systems 4(3): 313-332.

[29] Penman, H.L. (1956). Estimating evaporation. - Transaction of American Geophysical Union 37(1): 43-50.

[30] Ren, M.E., Yang, J.Z. (1961): The problems of the physical regionalization of China. Acta Geographica Sinica 27: 66-74. (in Chinese) 
[31] Sjögersten, S. Wookey, P.A. (2009): The Impact of Climate Change on Ecosystem Carbon Dynamics at the Scandinavian Mountain Birch Forest-Tundra Heath Ecotone. - A Journal of the Human Environment 38(1): 2-10.

[32] Thornthwaite, C.W. (1948): An approach toward a rational classification of climate. Geographical Review 38: 57-94.

[33] Woodward, F.I. (1987): Climate and plant distribution. - London: Cambridge University Press.

[34] Wu, Z.F. (2002): Eco-climatic study on vegetation transition zones in Northeast China. Scientia Geographica Sinica 22(2): 219-225. (in Chinese)

[35] Wu, Z.F., Jin, Y.H., Liu, J.P., Shang, L.N., Zhao, D.S. (2003): Response of vegetation distribution to global climate change in Northeast China. - Scientia Geographica Sinica 23(5): 564-570. (in Chinese)

[36] Xu, W.D. (1980): A discussion on the border line of vegetational regions of Xinganling Mountain in China. - Journal of Integrative Plant Biology (4): 63-67.

[37] Xu, W.D. (1985): Kira's temperature indices and their application in the study of vegetation. - Chinese Journal of Ecology 4(3): 35-39. (in Chinese)

[38] Xu, W.D., He, X.Y., Chen, W., Zhang, Y., Li, H.M., Liu, C.F. (2003): Flora and vegetation types in the downtown area of Shenyang. - Chinese Journal of Applied Ecology 14(12): 2095-2102. (in Chinese)

[39] Xu, W.D., He, X.Y., Chen, W., Liu, C.F., Zhao, G.L., Zhou, Y. (2008): Ecological division of vegetations in Northeast China. - Chinese Journal of Ecology 27(11): 18531860. (in Chinese)

[40] Yang, Q.Y., Li, S.C. (1999): Some themes on eco-regionalization of China. - Acta Ecologica Sinica 19(5): 596-601. (in Chinese)

[41] Yim, Y., Kira, T. (1975): Distribution of forest vegetation and climate in the Korea Peninsula. I. Distribution of some indices of thermal climate. - Japanese Journal of Ecology 25: 77-88.

[42] Yim, Y. (1977): Distribution of forest vegetation and climate in the Korea Peninsula. III. Distribution of tree species along thermal gradient. - Japanese Journal of Ecology 27: 177-189.

[43] Zhao, Y.L., Zhang, L.J. (1999): Study on method of quantitative assessment of fragile environment. - Chinese Geographical Science 9(2): 141-145.

[44] Zhou, G.Y. (1981): Discussion on the boundary of warm temperature deciduous broadleaf forest region in China. - Acta Phytoecologia et Geobotanica Sinica 5(4): 302-307. (in Chinese) 